Uluslararası Mühendislik

Cilt/Volume:13 Sayı/Issue:3 Aralık/December 2021 Özel Sayı/Special Issue

\title{
Sıvı Hidrojen ve Sıvı Oksijen ile Çalışan bir Roket Motorunun Rejeneratif Soğutma Analizi
}

\section{Regenerative Cooling Analysis of Rocket Engine Operated by Liquid Hydrogen and Liquid Oxygen}

\author{
Safa Korkmaz $^{1}$ iD, Hayri Yaman² iD \\ ${ }^{1}$ Milli Savunma Bakanlı̆̆g, Posta Kodu ve Ankara, Türkiye \\ ${ }^{2}$ Kırıkkale Üniversitesi Motorlu Araçlar ve Ulaştırma Teknolojisi Bölümü, 71450 ve Kırıkkale, Türkiye
}

Başvuru/Received: 07/10/2021

Kabul / Accepted: 25/12/2021

Çevrimiçi Basım / Published Online: 31/12/2021

Son Versiyon/Final Version: 31/12/2021

\section{$\ddot{\mathbf{O} z}$}

Sıvı yakıtlı roket motorları yüksek yanma sıcaklıklarında uzun süre çalışmaları nedeniyle soğutulmaları gerekmektedir. Sıvı yakıtlı roket motorlarında soğutma sistem tasarımı en önemli konuların başında gelmektedir. Çünkü roket motorları çalışma esnasında 2500-3500 K sıcaklığa maruz kalmakta ve bu sıcaklık aralığı çoğu metalin ergime sıcaklığının üzerindedir. Sıvı yakıtlı roket motorlarının kararlı ve güvenli bir yapıda çalışması için farklı soğutma teknikleri uygulanmaktadır. Genellikle sıvı yakıtlı roketlerde rejeneratif soğutma yöntemi kullanılmaktadır. Bu çalışmada $100 \mathrm{kN}$ itki üreten bir sıvı oksijen ve sıvı hidrojen ile çalışan roket motorunun rejeneratif eş eksen soğutma sistemi ve roketin yüksek sıcaklığa maruz kalan kısımları zirkonya (ZrO2) kaplamalı tasarımı yapılmıştır. Tasarımı yapılan roket yedi bölgeye ayrılmış ve soğutma analizi RPA programı aracılığı ile nümerik olarak yapılmışıı. Soğutma kanalına 23.75 MPa basınçta ve $45 \mathrm{~K}$ sıcaklıkta giren sıvı hidrojenin $23.095 \mathrm{MPa}$ ve $141.21 \mathrm{~K}$ sıcaklıkta kanaldan çıkması ile karalı soğutma koşulunun sağladığı görülmüştür.

\section{Anahtar Kelimeler}

"Sivı Yakıtll Roket, Rejenaratif Soğutma, Analiz"

\begin{abstract}
Liquid fueled rocket engines have to be cooled due to their long-term operation at high combustion temperatures. Cooling system design is one of the most important issues in liquid fueled rocket engines since rocket engines are exposed to 2500-3500 K temperature during operation and this temperature range is above the melting temperature of most metals. Different cooling techniques are applied for the safe and stable operation of liquid fueled rocket engines. Generally, regenerative cooling method is used in liquid fueled rockets. In this study, the regenerative coaxial cooling system was designed for rocket engine which produces $100 \mathrm{kN}$ thrust with liquid oxygen and liquid hydrogen. The parts of the rocket exposed to high temperatures were coated with zirconium oxide $(\mathrm{ZrO} 2)$. Numerical analysis of rocket was carried out through the RPA program by dividing into seven zones. It was observed that liquid hydrogen entering the cooling channel at $23.75 \mathrm{MPa}$ pressure and $45 \mathrm{~K}$ temperature provides stable cooling conditions with the output of $23.095 \mathrm{MPa}$ and $141.21 \mathrm{~K}$ temperature.
\end{abstract}

Key Words

"Liquid Propellant Rocket, Regenerative Cooling, Analysis" 


\section{Giriş}

Siv1 yakıtlı roket motorları; oksitleyiciyi ve yakıtı sıvı formda kullanan kimyasal roket motorlarıdır (Sutton ve Biblarz, 2016). Roketlerin tahriki için gerekli enerji, roket yakıtlarının bünyesinde bulunan kimyasal enerjinin kinetik enerjiye çevrilmesiyle sağlanır. Kimyasal yakıtın roket yanma odasında yüksek basınç altında yakılması esnasında ortaya çıkan gazın sıcaklığı $4500 \mathrm{~K}$ kadar yükselebilmektedir. Yüksek basınç ve sıcaklıkta üretilen gaz nozul vasıtasıyla yüksek hız kazandırılarak roketten dışarı atılması ile itki kuvveti üretilmektedir (Ward, 2010).

Sıvı yakıtlı roketlerde yanma sıcaklıkları genellikle 2500-3500 K arasında değişmekte ve buna karşın birçok metalin ergime noktası $2000 \mathrm{~K}$ altında kalmakatadır. Bu sebepten dolayı sıvı yakıtlı roketlerin yanma odası ve nozulun soğutulması gerektirmektedir. Kısa süreli operasyonlar için soğutma sistemi yerine ısı kuyusu olarak görev yapan yeterince kalın yanma odası duvarı kullanılabilmektedir. Uzun süreli operasyonel çalışmalarda ise bir soğutma sistemi kullanılmalıdır (Huang ve Huzel, 1971; Turner, 2006).

Yakıt veya yakıtla oksitleyicinin birlikte, enjektöre gönderilmeden önce nozul ve yanma odası duvarlarının içinde bulunan soğutma kanallarından dolaştırılmaktadır. Soğutucu sıvı yakıt, taşınım yoluyla ısı transferi yaparak yanma olayında meydana gelen isıyı emmekte ve duvar sıcaklıklarını istenen seviyede tutmaktadır (Kim vd, 2014; Song ve Sun, 2016). Bu olaya rejeneratif soğutma denilmektedir. Roketlerde en yaygın biçimde kullanılan soğutma sistemidir. Yüksek özgül itki ve kimyasal kararlılık istenen yüksek sıcaklık ve basınç uygulamalarında kullanılmaktadır. Şekil l'de rejeneratif soğutma sisteminin şematik gösterimi verilmiştir (Dhara vd, 2020; Sichler vd, 2018).

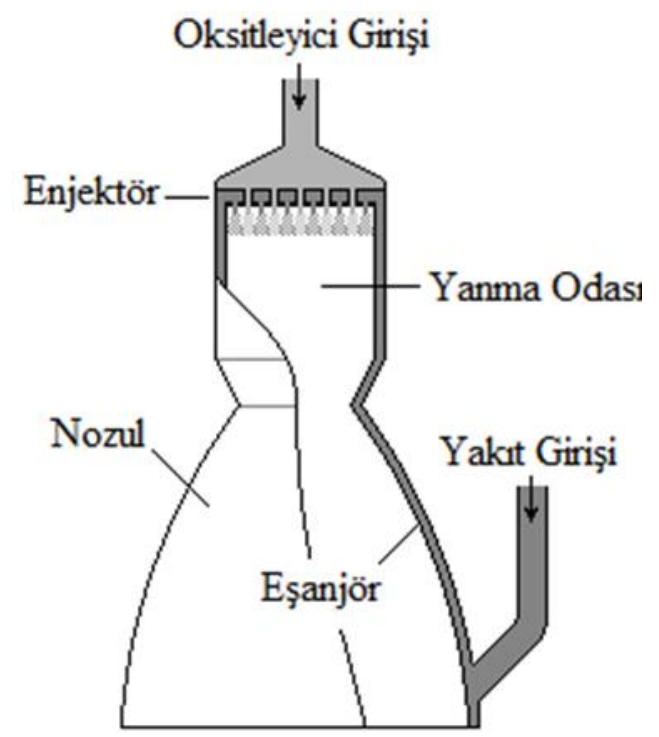

Şekil 1 Rejeneratif soğutma sisteminin şematik gösterimi

\section{Metaryel ve Metod}

Sıvı yakıtlı roket motorları yüksek yanma sıcaklıklarına ve uzun süre çalışmaları nedeniyle soğutulmaları gerekmektedir (Ulas ve Boysan, 2013). Roket motorlarında yanma sıcaklığı birçok metalin erime sıcaklığından yüksektir. Bu yüzden roket motorlarının düzgün bir şekilde çalışmasına devam için soğutma sistemi hayati bir rol üstlenmektedir. Sıvı yakıtlı roketlerde genellikle rejeneratif soğutma yöntemi kullanılmaktadır. Roket motorlarında 1sı transfer mekanizması Şekil 2'de görüldüğü gibi sırasıyla sıcak gazlardan roket motor duvarının iç kısmına ardından roket motor duvarı aracılığı ile roket motor duvarı soğutucu yüzeyine son olarak soğutma sıvısına doğru gerçekleşmektedir. 


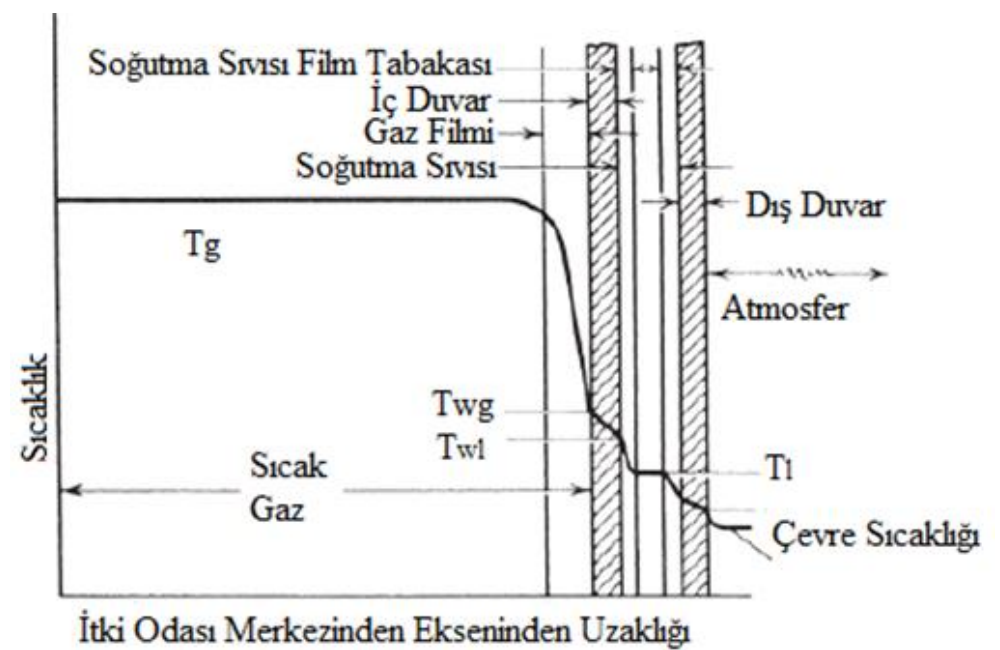

Şekil 2 Soğutucu sıvı ile soğutulan roket motorunun 1sı transfer mekanizması

Gaz tarafından roket motoru iç duvarına 1sı transferi Denklem 1 ile gösterilmektedir. Burada q 1sı akısı, hg 1sı transfer katsayısı, Tg gaz sıcaklığını ve Twg roket motoru iç duvar sıcaklığını ifade etmektedir.

$$
\mathrm{q}=\mathrm{h}_{\mathrm{g}}\left(\mathrm{T}_{\mathrm{g}}-\mathrm{T}_{\mathrm{wg}}\right)
$$

Roket motorunu iç duvarı boyunca 1 sı transferi Denklem 2 ile gösterilmektedir. $\kappa$ duvar malzemsinin termal iletkenlik katsayısını ve Twl soğutma sıvısı tarfaındaki roket motor duvar sıcaklığını ifade etmektedir.

$$
\mathrm{q}=\frac{\kappa}{\mathrm{t}_{\mathrm{w}}}\left(\mathrm{T}_{\mathrm{wg}}-\mathrm{T}_{\mathrm{wl}}\right)
$$

Roket motor duvarından soğutma sıvısına doğru 1sı transferi denklem 3'te olduğu gibi ifade edilmektedir. Soğutma sıvısı 1S1 taşınım katsayısı hl ile gösterilmektedir ve Tl ise soğutma sıvısı sıcaklı̆̆ıdır.

$$
\mathrm{q}=\mathrm{h}_{\mathrm{l}}\left(\mathrm{T}_{\mathrm{wl}}-\mathrm{T}_{\mathrm{l}}\right)
$$

Denklem 1, 2 ve 3 birlikte tekrar yazıldığı zaman Denklem 4 elde edilmektedir.

$$
\mathrm{q}=\frac{\left(\mathrm{T}_{\mathrm{g}}-\mathrm{T}_{\mathrm{l}}\right)}{1 / \mathrm{h}_{\mathrm{g}}+\mathrm{t}_{\mathrm{w}} / \kappa+1 / \mathrm{h}_{1}}
$$

Gaz tarafinda 1sı transfer katsayısı hg Bartz kolerasyonu kullanılarak Denklem 5'ten hesaplanabilmektedir.

$$
\begin{aligned}
& \mathrm{h}_{\mathrm{g}}=\left[\frac{0.026}{\mathrm{D}_{\mathrm{t}}^{0.2}}\left(\frac{\mu^{0.2} \mathrm{c}_{\mathrm{p}}}{\operatorname{Pr}^{0.6}}\right)\left(\frac{\mathrm{P}_{\mathrm{c}} \mathrm{g}}{\mathrm{c}^{*}}\right)^{0.8}\left(\frac{\mathrm{D}_{\mathrm{t}}}{\mathrm{R}}\right)^{0.1}\left(\frac{\mathrm{A}_{\mathrm{t}}}{\mathrm{A}_{\mathrm{x}}}\right)^{0.9}\right] \lambda \\
& \lambda=\frac{1}{\left[0.5\left(\frac{\mathrm{T}_{\mathrm{wg}}}{\mathrm{T}_{\mathrm{g}}}\right)\left(1+\frac{\mathrm{k}-1}{2} \mathrm{M}_{\mathrm{g}}^{2}\right)+0.5\right]^{0.68}\left[0.5+\frac{\mathrm{k}-1}{2} \mathrm{M}_{\mathrm{g}}^{2}\right]^{0.12}}
\end{aligned}
$$

Denklem 5 ve 6 da $\mu$ viskoziteyi, Pr Prantl sayısını, $M_{g}$ mol ağırlını ifade etmektedir. Prantl sayısı boyutsuz bir sayıdır ve momentum yayılımının termal yayınım oranına eşittir. R nozul boğaz ortalama yarıçapıdır.

Siv1 yakıtlı roket motorunun rejeneratif soğutma analizi Rocket Propulsion Analysis (RPA) programı ile gerçekleştirilmiştir. Alexander Ponomarenko tarafindan geliştirilen RPA programı, roket motorlarının performans tahmini ve optimizasyonu için kullanılan bilgisayar destekli bir programdır (Munk vd, 2022). Roket motorlarının tasarımı ve analizi az sayıda parametre girilerek yapılabilmektedir. Bu sayede hem zaman hem de maliyet açısından üstün ve doğru sonuçların elde edilmesi sağlamaktadır (Ponomarenko, 2009, 2012). Sıvı Hidrojen - Sıvı Oksijen ile çalışan 100 kN'luk roket için duvar malzemesi olarak yüksek termal iletkenliğe sahip olan oksijensiz bakır seçilmiştir. Oksijensiz bakırın erime sıcaklığı $1350 \mathrm{~K}$ ve termal iletkenliği $390 \mathrm{~W} / \mathrm{m}$.K'dir.. Soğutma sistemi olarak rejeneratif soğutmayla birlikte roket iç yüzeyine termal bariyer kaplanması seçilmiştir. Termal bariyer malzemesi olarak yüksek sıcaklığa dayanıklı zirkonya ( $\mathrm{ZrO} 2)$ seçilmiştir. Zirkonyanın erime sıcaklığı $3000 \mathrm{~K}$ ve termal iletkenliği 3 W/m.K'dir. Soğutma sıvısı olarak Sıvı Hidrojen kullanılmaktadır. Rejenaratif soğutma kanalının boşluğu 2 mm olarak belirlenilmiştir. 
Tablo 1 Soğutma sistemini kademelerinin parametreleri

\begin{tabular}{cccc}
\hline Soğutma Aşamaları & Enjektöre Olan Uzaklığı $(\mathrm{mm})$ & Termal Bariyer Kalınlığı (mm) & İç Duvar Kalınlığı (mm) \\
\hline s1 & 0 & 0.22 & 6 \\
s2 & 51.84 & 0.2 & 6 \\
s3 & 180 & 0.17 & 5 \\
s4 & 330 & 0.15 & 6 \\
s5 & 350 & 0.12 & 6 \\
s6 & 390 & 0.05 & 6 \\
s7 & 440 & 0 & 6 \\
\hline
\end{tabular}

- Roketin soğutulması 7 aşamada sırasıyla s1'den s7'ye doğru yapılmıştır. Tablo 1'de soğutma aşamalarının parametreli gösterilmektedir. Tablo 1'deki parametrelerle oluşturulan roket soğutma sisteminin kesit görünümü Şekil 3 'te görülmektedir.

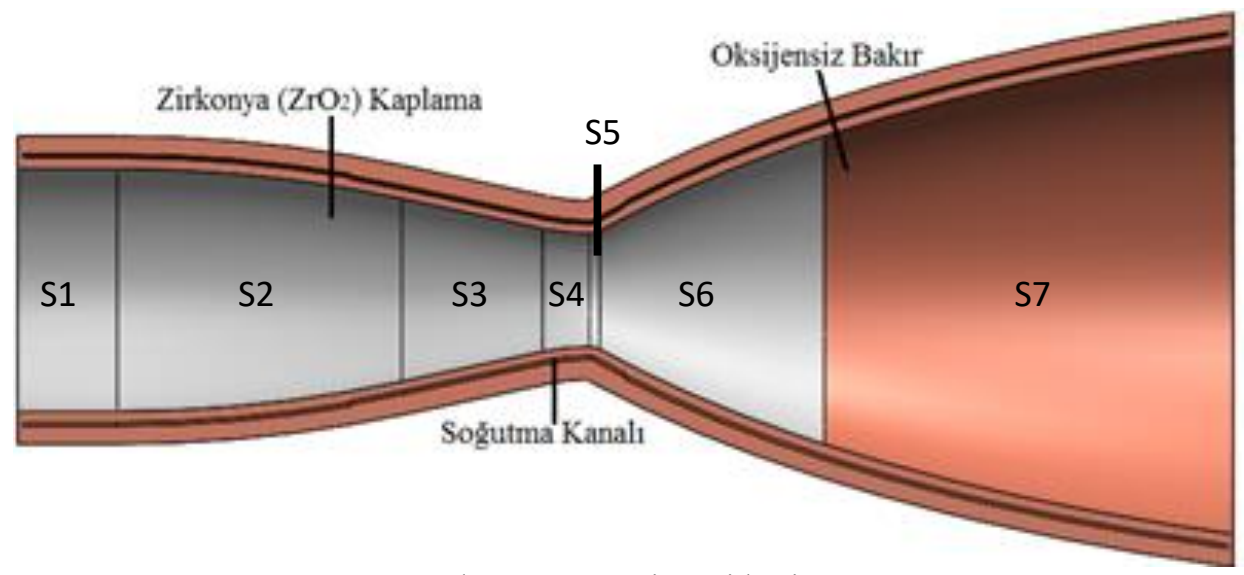

Şekil 3 Roket soğutma sistemi kesit görünüşü

\section{Bulgular}

RPA programı ile soğutma sistemi analiz edildiğinde roket duvarlarındaki sıcaklık değerleri Şekil 4'de verilmiştir. Soğutma sıvısı soğutma kanalına 23.75 MPa basınçla girmektedir ve 20.95 MPa basınçla çıkmaktadır. Soğutma sıvısının kütlesel debisi $4.33 \mathrm{~kg} / \mathrm{s}$ 'dir. Roket geometrisi boyunca zirkonya kaplama sıcaklığı 2638.24 K ile enjektörden 301.25 mm uzaklığında görülmüştür. Sıcak gaz tarafı duvar sıcaklığı en yüksek 1032.87 K iken duvar boyunca sıcaklık 1000 k altındadır. Soğutucu sıvı tarafındaki duvar sıcaklığı en yüksek $787.79 \mathrm{~K}$ olarak yanmanın başladı̆̆ı lokasyonda meydana gelmiştir.

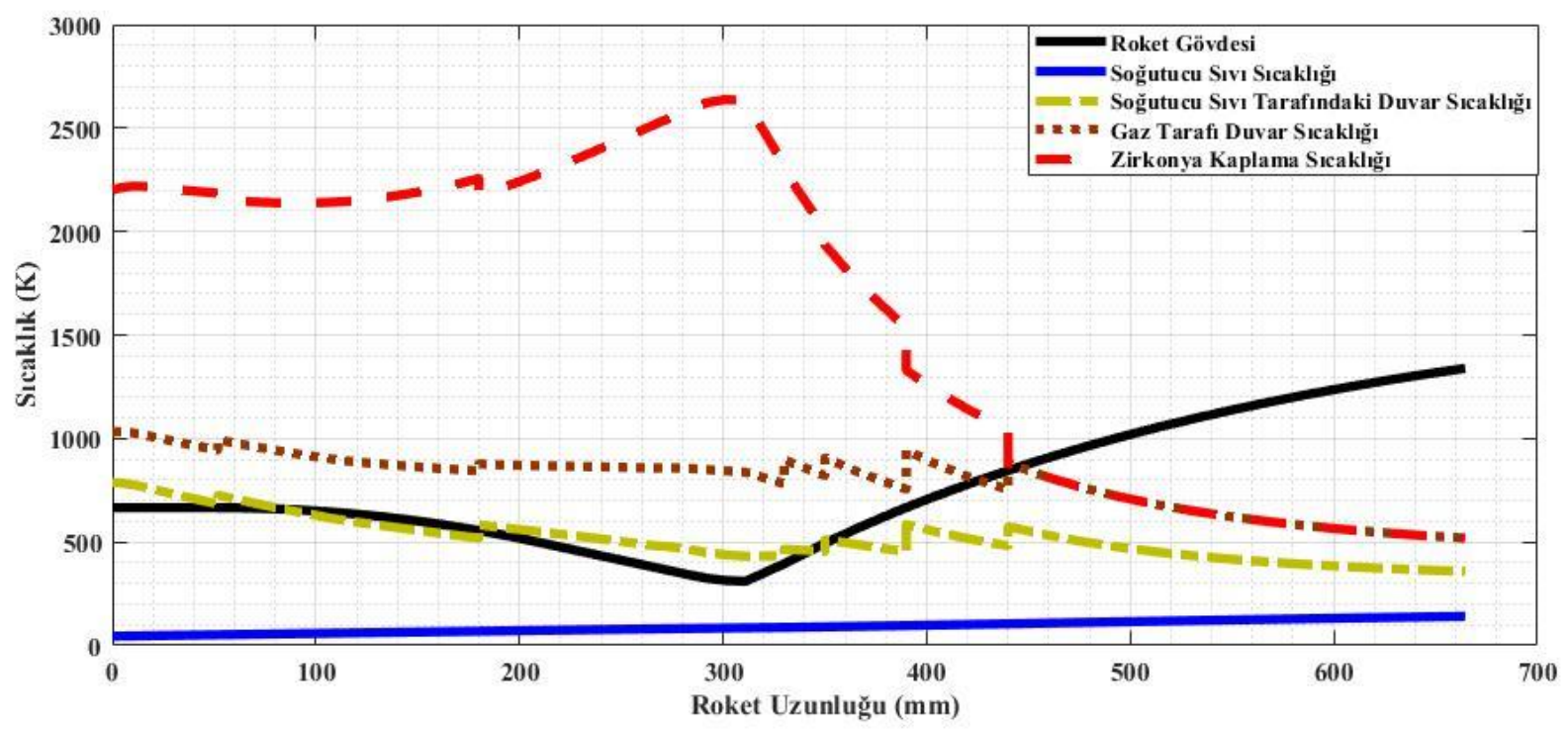

Şekil 4 Roket malzemesi sıcaklık grafiği 
Roket boyunca 1sı akısı dağılım grafiği Şekil 5'te gösterilmektedir. Şekil 5 incelendiğinde en yüksek 1sı akısı beklenildiği gibi yüzey alanının minumum olduğu nozul boğazında olmuştur.

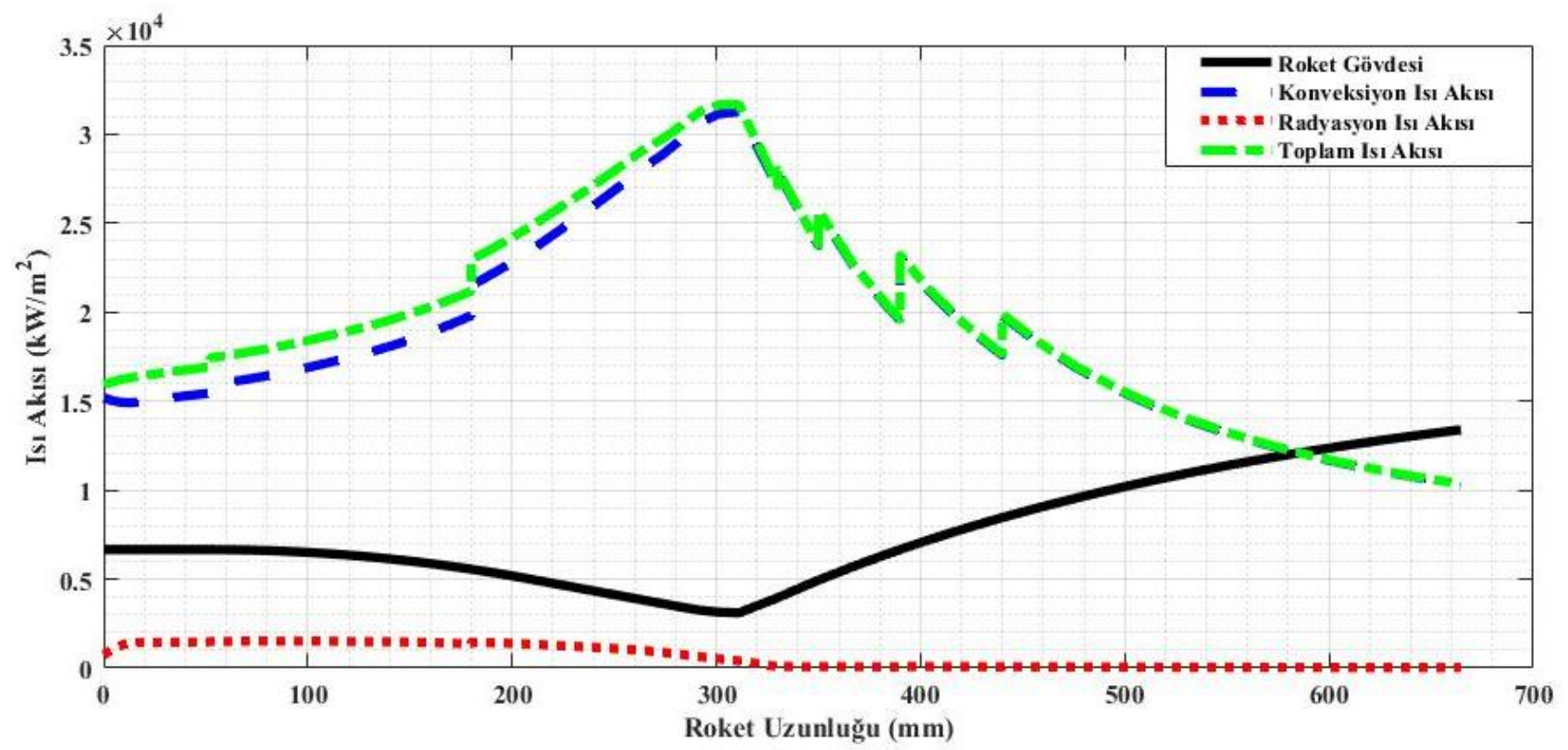

Şekil 5 Soğutma sistemini ısı akısı dağılım grafiği

Yapılan çalışma ile optimum soğutma için uygun yakıt debisi vasıtasıyla roketin herhangi bir problem yaşamadan çalışabilirliği belirlenmiştir. Kritik bölgelere zirkonya kaplaması ile yüksek sıcaklığa dayanımlı yapı oluşturulmuştur. Ayrıca yüksek ısıl iletkenliğe sahip olan oksijensiz bakır kullanımı sayesinde iyi bir ısı transferi ile roketin emniyetli çalışma koşulları sağlanmıştır.

\section{Tartışma ve Sonuç}

Bu çalışmada co-axial (eş eksenli) rejeneratif soğutma sistem tasarımı ve analizi yapılmıştır. Roket itki odası malzemesi olarak yüksek mukavemet ve 1sıl iletim özelliklerinden dolayı oksijensiz bakır seçilmiştir. Oksijensiz bakırın sıcaklığa bağlı olarak deformasyon, çarpılma ve erimesini engellemek için roket gövdesinin yüksek sıcaklığa maruz kalan kısımları zirkonya seramik malzemesi ile kaplanmıştır. Soğutma yedi kademe kullanılarak en efektif şekilde yapılmıştır. Soğutma sıvısı olarak rokette aynı zamanda yakıt olarak kullanılan sıvı hidrojen seçilmiştir. Soğutucu olarak kullanılan sıvı hidrojen, roketin soğutulması sonrası dışarı atılacak enerjiyi üzerine alarak yanma odasına rejeneratif kazançla gelmektedir. Böylece sıvı yakıtlı roket daha verimli çalışmaktadır. $\mathrm{Bu}$ rokette $45 \mathrm{~K}$ sıcaklık ile soğutma kanalına verilen sıvı hidrojen $141.21 \mathrm{~K}$ sıcaklığa çıkarak yanma odasına girdiği tespit edilmiştir.

\section{Referanslar}

Dhara, A., Kishan, P. M. ve Kannah, V. V. (2020). Design of Regenerative Cooled Cryogenic Rocket Engine.

Huang, D. H. ve Huzel, D. K. (1971). Design of Liquid Propellant Rocket Engines Second Edition.

Kim, S.-K., Joh, M., Choi, H. S. ve Park, T. S. (2014). Multidisciplinary Simulation of a Regeneratively Cooled Thrust Chamber of Liquid Rocket Engine: Turbulent Combustion and Nozzle Flow. International Journal of Heat and Mass Transfer, 70, 1066-1077.

Munk, D. J., Selzer, M., Seiler, H., Ortelt, M. ve Vio, G. A. (2022). Analysis of a transpiration cooled LOX/CH4 rocket thrust chamber. International Journal of Heat and Mass Transfer, 182, 121986.

Ponomarenko, A. (2009). RPA: Design tool for liquid rocket engine analysis.

Ponomarenko, A. (2012). Thermal analysis of thrust chambers. Software Manual, RPA: Tool for Rocket Propulsion Analysis.

Sichler, E., Montes, J. D. ve Chandler, F. O. (2018). One Dimensional Thermal Steady State Analysis and Procedure for a LowPressure Liquid Oxygen and Liquid Methane Rocket Engine. 2018 Joint Propulsion Conference içinde (s. 4602).

Song, J. ve Sun, B. (2016). Coupled Numerical Simulation of Combustion and Regenerative Cooling in LOX/Methane Rocket Engines. Applied Thermal Engineering, 106, 762-773.

Sutton, G. P. ve Biblarz, O. (2016). Rocket propulsion elements. John Wiley \& Sons. 
Turner, M. J. L. (2006). Rocket and Spacecraft Propulsion (2. bs.). Springer-Verlag Berlin Heidelberg.

Ulas, A. ve Boysan, E. (2013). Numerical analysis of regenerative cooling in liquid propellant rocket engines. Aerospace Science and Technology, 24(1), 187-197.

Ward, T. A. (2010). Aerospace propulsion systems. John Wiley \& Sons. 